\title{
Can Music Convey Semantic Content? A Kantian Approach
}

When people are asked to describe what they hear in instrumental music, their answers are remarkably different. Some listeners claim to hear only "the notes" or "the music itself"; others, most often those with some formal music education, can hear underlying structural patternssonata forms, themes, variations, and recapitulations. While a great many listeners find the expressive aspects of music particularly striking, for others music is a stimulus to the imagination, and listening can inspire flights of fancy. There are those who go further in assuming that music carries a great deal of extramusical content, beyond its expressive properties. Particular musical works have been described as "profound" or "true" or even as having moral value. Certain listeners claim to hear music, at least sometimes, as meaning-bearing: The music seems to be saying something to them, if only they could penetrate its secrets.

What is going on here? Can music in fact convey something like a semantic content, with "semantic" understood as whatever systematically contributes to the sense, reference, or truth of propositions? In this article I explore recent philosophical work on these questions and offer some tentative answers. The arguments against the view that music is a type of language or a "language of emotions" are well known, and I will not rehearse them here. ${ }^{1}$ While such arguments might make listeners who hear music as meaning-bearing feel inadequate or guilty about their reactions, I doubt they have succeeded in making such listeners cease hearing music as semantically contentful. This is not surprising: Such arguments usually aim at conceptual clarity, not conversion to a particular aesthetic approach.

In the philosophical literature that deals di- rectly or indirectly with musical content, questions of "meaning," musical "semantics," extramusical "content," and the possibility of music's cognitive value are not sharply distinguished. ${ }^{2}$ This is not surprising, and I do not think it is a flaw or an indication of confusion. If music can be meaningful (analogous to the way a sentence is meaningful, rather than the way a favorite stuffed toy is meaningful to a child), then this meaning will be describable as the music's "content." If music has cognitive, as well as hedonic value, then this value can be assessed in terms of its meaning or content. I will briefly consider two philosophical attempts to account for music's meaning (loosely construed), followed by a look at Peter Kivy's argument for the rejection of the possibility of musical semantic content. I will propose a different approach.

The debate over musical content occurs on two levels: Arguments over how best to characterize the "meaning" of particular passages and the metaquestion of whether it is even appropriate to say that music can have an extramusical content. These questions are too often discussed in isolation from one another, the first tending to be the preserve of musicologists and the second of "card-carrying" philosophers. While I am more interested in the metaquestion, I am convinced that to come to an adequate answer the variety of listeners' responses to music must also be taken seriously. So I will begin by quoting some descriptions of music as heard.

Philosopher and occasional composer Roger Scruton has said that Bach's D minor Chaconne for solo violin provides an effect of "titanic strain, as of a giant Atlas bearing the burden of the world's great sadness," and that the technical difficulty of this work is "inseparable from its message." 3 Susan McClary, a contemporary 
musicologist, finds that the third movement of Beethoven's Ninth Symphony "offers the image of a world in which pleasure is available without thrusting desire, where tenderness and vulnerability are virtues rather than fatal flaws." 4 The professional cellist and writer Alexander Ivashkin has written that Alfred Schnittke's enormous popularity in Russia in the 1970s and 1980s was due to the fact that in his work, listeners found the "metaphysical ideas and spiritual values" that were lacking in official life and culture.5 Ivashkin also says that Schnittke's musical vocabulary, like that of Messiaen and Schostakovich, reveals the difference between "the conceivable and the audible." 6 Music critic and BBC announcer Ivan Hewett finds the music of Arvo Pärt and Henryk Górecki wanting because "genuine religious music must engage with doubt. ..."7

I have chosen these examples carefully to dispel the suggestion that only naïve and musically unsophisticated listeners hear music as meaning-bearing. Anyone who sought to argue that the ascription of semantic content to music was made only by listeners who lacked technical training or vocabulary would have to grapple with these and similar descriptions by performers, composers, musicologists, and philosophers.

Turning now to explicit philosophical discussion of the possibility that music may have an extramusical semantic or cognitive content, I will briefly consider arguments in favor by James O. Young and by Kendall Walton.

In his article, "The Cognitive Value of Music," Young attempts to defend the thesis that music, even so-called "absolute" music (which lacks a text or program) is valuable as a source of knowledge and can help us understand nonmusical matters. According to Young, the arts contribute to our knowledge by means of immediate demonstration-placing someone in a position to recognize that something is the case. Immediate demonstration can be achieved using interpretative or affective representation. In the first, something about an object is made apparent to an audience; techniques facilitating interpretive representations include amplification and simplification. For example, in the work of Dickens, aspects of character are amplified or exaggerated so that the audience is in a better position to understand the features in question. An affective representation puts an audience in a position to know something about an object by making them feel a certain way about it. Affective representations may be extroverted, when the affects are directed outward, or introverted, when the aroused affects are themselves the objects of knowledge. ${ }^{8}$

Music employs both interpretive and affective representation. An example of interpretive representation is when music indirectly represents emotional states by representing the movements with which those emotions are associated. The representation of these movements can provide audiences with insight into certain emotional states; "Listening to a skillfully composed piece, listeners can realize, for example, what it is like simultaneously to feel attracted to something and hesitant about embracing it."9 More commonly, music employs affective representation-it arouses feelings in some listeners and in so doing, shows them something about the affect in question. ${ }^{10}$ For example, in listening to the music of the nineteenth century, one can gain insight into what it was like to adopt a romantic perspective on life.

Although Young is to be congratulated for bringing conceptual clarity to such a nebulous topic, it must be admitted that his conclusions are very modest: Some (not all) music may have cognitive value to some (not all) listeners. The cognitive value of music turns out to be fairly commonplace: Surely everyone who has tried to quit smoking or follow a diet knows what it is like to feel attracted to something and hesitant about embracing it. While listening to sad music might make one better able to appreciate varieties and gradations of sadness, such knowledge might also be gained by reading a novel or talking to a sad person. It seems unlikely that listening to music could convey anything more or better than other courses one might follow.

Kendall Walton is concerned with meaning "for" the listener, rather than with the semantic meaning of music more narrowly construed. He begins by trying to specify how music differs from other more obviously representational arts, and considers the possibility that the semantic content of music is more general than that of figurative painting, literature, etc. ${ }^{11}$ While it seems presumptuous, even "unmusical" to suggest that a sonata is about, say, the Trojan war, or even warfare in general, it makes sense to suggest that 
music can be about struggle in general. Depending on a listener's personality, interests, and immediate situation, he or she might hear a struggle in music as a clash between two people, an internal battle, or a struggle for dignity under oppression.

Walton then turns to the "puzzle" of how a musical passage gets connected to the idea (say) of struggle in general, without somehow portraying a particular instance of struggle. His solution, as I understand it, is that music often calls for imaginative introspecting. We imagine that our actual introspective awareness of auditory sensations is an experience of being aware of our states of mind: "My suggestion is not that the music portrays an objective event or circumstance, and then induces the listener to imagine responding to it in a certain manner; it just induces the listener to imagine the experience of responding to an object of a certain sort." However, for Walton, the fact that music elicits imaginings does not justify talk of musical meaning or semantic content.

Walton is definitely on the right track in focusing his investigation into musical meaning on the listener's experience. Yet Walton does not get any further than Young with regard to the possibility of musical content, and his account (at least as I understand it) is somewhat puzzling. I know what it is to imagine, and to introspect, but I am not sure what it would be to imagine that I introspect while listening to music. Walton hopes to facilitate "the daunting task of uncovering the secret of [music's] power," but there is little that is specifically $m u$ sical in his account. It could serve just as well as an account of why different people see various things in Rorschach blots or cloud formations. What is it about music that elicits its particular imaginings? Without a fuller account of how meaning for the listener is underwritten, it is difficult to see how there can be even the narrowest consensus among listeners. While it is uncontroversial to say that a particular passage might make me imagine a struggle between weather patterns and symbolize for you the struggle between good and evil, what are we to make of the listener who hears no struggle whatsoever?

Turning now to arguments against the possibility of semantic content in music: Kivy contends that Schopenhaur's views on music, minus their metaphysical niceties, are widely held among musical scholars. Accordingly, music has a hidden content, not apparent on its surface, which is in need of hermeneutical revelation. ${ }^{12}$ Kivy develops his critique of the possibility of a "hidden content" in music through a consideration of two recent attempts by musicologists to find such a content in nonprogrammatic music. ${ }^{13}$ Even if we knew, for example, that Bach intended the Art of the Fugue to express the proposition, "I seek salvation," we cannot conclude that this is what the music actually expresses. Music cannot express this proposition, so Bach's purported intention simply fails. While particular structural features of the Art of the Fugue can indeed represent seeking and reaching a goal, how do we know which goal is represented? We have no more right to say that the goal is "salvation" than to say that it is victory over enemies or returning home after a long journey. What, exactly, is the "message concerning tolerance" expressed in Haydn's symphonies? Even if it could be shown that the music refers to tolerance (which Kivy doubts), how do we know what Haydn wanted to say about tolerance? And even if we had evidence (say, in a letter) that Haydn wanted to endorse Shaftesbury's views on tolerance in his music, it seems silly to say that we could gain a better understanding of Shaftesbury by listening to Haydn.

We saw earlier that Walton assumes that it is unproblematic to say that music can be "about" struggle in general. Kivy, in contrast, argues that "aboutness" is a semantic concept, and a causal connection between music's expressive properties and thinking about those properties is not enough to establish it. ${ }^{14}$ It simply begs the question to go from the fact that many works of music have expressive properties as part of their structure to the conclusion that these properties make up an emotive, semantic content. ${ }^{15}$ Furthermore, it is not enough to establish that music can be about some extramusical subject; defenders of musical "meaning" also need to show why musical "aboutness" is interesting. Kivy finds it difficult to see how music could say anything valuable regarding what it is about. ${ }^{16}$ So even if we allow that a certain composition is about struggle in general, it still needs to be shown that the music could tell us or show us something interesting about struggle.

Kivy does not say what would be necessary to 
establish the concept of "aboutness" in music. He offers no suggestions as to the necessary and sufficient conditions or other indications of how to discuss "aboutness" in the arts. I suspect he does not because he realizes how difficult it would be to do this with any rigor. I agree with Jerrold Levinson who has argued that a loose, informal sense of aboutness is valuable for aesthetics. ${ }^{17}$ Indeed, restricting the notion of aboutness would excessively constrict our ability to discuss other arts.

For example, literary works often seem to be "about" things not explicitly discussed. If someone were to ask me what Chekhov's short story "The Lady with the Small Dog" was about, I might answer that it was about an adulterous love affair between a man and a younger woman whom he meets on vacation. I might also say that it was about the power of love to triumph over the cynicism and despair of middle age. What is my warrant for saying this? My analysis of the story's meaning required interpretation, although I have not claimed to reveal any hidden content or say what Chekhov "really" meant. I would likely be able to convince other readers that my interpretation was plausible by pointing to aspects of the story-for example, the change from the protagonist's initial world-weary boredom to his increased attentiveness and joy in his children by the end of the story.

What is the relevance for music? Literary works, unlike music, often have an unambiguous propositional content. However, literary works are not always about their propositional content. To determine what a literary work is about requires judgment and careful reading, with attention to details, nuances, and sometimes also to the context in which the work was written or initially received. These various factors cannot be enshrined in a formula or given in the form of necessary and sufficient conditions. Despite such difficulties, we can talk profitably of what literary works are "about," and offer evidence in favor of rival interpretations. It is similarly possible to discuss what a particular musical work may be about, despite the conceptual difficulties involved. Furthermore, the clarity of a literary work's propositional content does not invariably make possible a clear determination as to what the work is about. So, lack of agreement as to the "content" of a musical work should not necessarily prohibit speculation as to what that work is about.

We have seen that the sophisticated attempts by Young and Walton to make sense of musical "content" proved disappointing. A philosophically rigorous analysis of musical content allows us to say far less than is indicated in the experience of many listeners. Kivy would have an answer to my qualified defense of musical "aboutness": Defenders of musical content have been misled by analogies between music and the more obviously "contentful" arts of literature and representational painting. And his arguments against the presence of a complex extramusical content in the music of Bach and Haydn seem fairly devastating. Attempts to expound the "hidden meaning" of instrumental music in propositional terms seem doomed to fail for the reasons that Kivy indicates-even if we allow that music can refer, how can we tell whether it endorses or condemns, and how can music tell us the precise terms in which it endorses or condemns?

Kivy accords respect to those with whom he disagrees, and gives their claims and arguments the serious treatment they deserve. What he fails to do, however, is to take seriously their listening experiences (all the while insisting, plausibly, that his listening experience must be taken seriously). If Kivy is right, and defenders of musical content (both musicologists and philosophers) have been misled by analogies between music and literature, what does this say about music and about the listener's experience? What can we learn from such misleading analogies (if that is indeed what they are)? The musicologists Kivy attacks certainly have the capability to make sense of their experience in theoretical and musicostructural terms. Why, then, do they choose to describe music according to notions perhaps more appropriate for literature? It may be easy to dismiss the experiences of untrained listeners, but there is little good reason not to take seriously the experiences of performers and musicologists, even if there is hardly consensus among them.

Is the debate over musical content doomed to end in a stalemate between those who "hear what they hear" and those who insist that for sound philosophical reasons, those in the first group cannot possibly make the music responsible for what they hear? Does philosophical rigor 
insist that we condemn those who insist on the reality of extramusical content? Only if the debate continues in the manner that it has. I believe there is a more fruitful approach: Rather than continuing to ask "Does music have an extramusical content or meaning?" let us consider the question "What is it about the experience of listening to music, such that listeners frequently experience what they hear as carrying semantic weight?" What is significant about music, such that it encourages some listeners to project, associate, or invest it with semantic content? While I would not defend the existence of hidden messages in instrumental music, I would like to try to understand the ground of the possibility for claims of hidden content. My tentative answer is based on a reading of Kant's Critique of Judgement, specifically his analysis of aesthetic ideas.

Aesthetic ideas and rational ideas are counterparts of one another, comparable to two sides of a coin. A rational idea is a concept of the mind to which no sensible intuition or representation of the imagination can be adequate. Kant's example of a rational idea is the kingdom of the blessed. An aesthetic idea is a (sensible) representation of the imagination that brings about much thought, but to which no definite thought or concept is commensurate. It is difficult to provide an example of an aesthetic idea, as they cannot be completely compassed and made intelligible by language. ${ }^{18}$

According to Kant, the poet (one is tempted to say, the creative artist, more generally) tries to express rational ideas by using sensory means. That is, he tries to give the appearance of objective reality to certain concepts that lie beyond the bounds of experience. Or, if the artist deals with things of which experience is possible — death, the emotions, vice, etc.-he tries to present these things with a "completeness" they lack in nature. In this type of creative work, the artist's faculty of aesthetical ideas is manifest (§ 49).

Closely linked to aesthetical ideas are the aesthetical attributes. These are forms that the artist uses to make us think of rational ideas. The aesthetical attributes are "approximate representations of the imagination" and express the consequences bound up with a given concept and its relationship to other concepts. However, the aesthetical attributes do not simply present given concepts. These concepts, as rational ideas, cannot be adequately represented; and if these concepts are given in experience, they lack a certain completeness. The aesthetical attributes of rational ideas "furnish" aesthetic ideas; that is, they enliven the mind by alerting it to the possibility of an unlimited range of related representations ( $(49)$. Because aesthetic ideas are representations of the imagination for which an adequate concept can never be found, they cannot be cognized as knowledge. Similarly, a rational idea cannot be cognized as knowledge because it involves a concept corresponding to which no intuition can be given. Aesthetic ideas are inexponible (ineffable) representations of the imagination, meaning that they cannot be conveyed to others through language ( $\$ 57, \mathrm{Re}$ mark I).

Kant's examples of aesthetical attributes are not very illuminating: The aesthetical attribute of the king of heaven (a rational idea) is Jupiter's eagle with lightning in its claws. By way of further explication he analyzes a poem by Frederick the Great, which many subsequent commentators have found notable only for its banality (§ 49). A more illustrative example is helpful here: "The act of Divine creation" is a rational idea that is not given in experience. Michelangelo tried to evoke or "realize to sense" this idea in his well-known fresco of two outstretched fingers about to touch one another (God's hand touching Adam's). The aesthetic ideas expressed by the fresco-impossible to convey adequately in language - might include God's benevolence and wisdom, the fundamentally dependent and contingent nature of human life, and the perfection of divine design. The aesthetical attribute by which these ideas are evoked is the form of Michelangelo's fresco; that is, the perceptual qualities inherent in it and their relations to one another, as perceived by a subject.

Kant indicates that music can express aesthetic ideas:

Thus as modulation is, as it were, a universal language of sensations intelligible to every man, the art of tone employs it by itself alone in its full force, viz. as a language of the affections, and thus communicates universally according to the laws of association the aesthetical ideas naturally combined therewith. Now these aesthetical ideas are not concepts or determinate thoughts. Hence the form of the composition 
of these sensations (harmony and melody) only serves instead of the form of language, by means of their proportionate accordance, to express the aesthetical idea of a connected whole of an unspeakable wealth of thought, corresponding to a certain theme which produces the dominating affection in the piece (§ 53).

We see here Kant's acceptance of the notion of a universal "language of passions," conveyed through the intonation of the speaking voice, which can in turn be expressed in music. In commenting on this passage, Kivy claims that with the integration of the notion of aesthetic ideas, Kant transforms the "shopworn" eighteenth-century notion of the Affectenlehre into something "entirely novel" and "indelibly marked with the signature of the third Critique."19 However, Kivy's enthusiasm is shortlived, as Kant seems to back away from the insights expressed above in favor of a physicalistic account of musical experience:

It is not the judging the harmony in tones or sallies of wit, which serves only in combination with their beauty as a necessary vehicle, but the furtherance of the vital bodily processes, the affection that moves the intestines and the diaphragm - in a word, the feeling of health. . . . In music, this play proceeds from bodily sensations to aesthetical ideas (the objects of our affections), and then from these back again to the body with redoubled force. $(\$ 54)$

According to Kivy, this passage gives us "nothing more than the standard, pre-critical explanation in the British manner," which Kant had already put behind him in the "Analytic of the Beautiful." 20 Kivy conjectures that Kant failed to live up to the promise of his earlier insights about music and aesthetical ideas ( $\$ 53$, quoted above), because of his "almost complete ignorance" of music as an art, including his ignorance of the larger elements of musical form. ${ }^{21}$ What Kant was groping toward in his application of aesthetic ideas to music, Kivy believes, was an attempt to capture "that feeling of logical coherence we have, but cannot state in conceptual terms, in a well wrought musical structure, a feeling of connected discourse." 22

I cannot share Kivy's view that the aesthetical ideas that Kant thought music able to convey were ideas related (exclusively) to its formal structure. For one thing, if Kant really was as ignorant of music's formal properties as Kivy and other commentators believe, it would seem unlikely that he would elevate musical form to the status of an aesthetic idea. None of the examples that Kant gives of rational ideas have to do with the form of an artwork. Form rather pertains to the aesthetic attributes - those features of an artwork that get us to think of aesthetic ideas. It is more plausible that the "connected whole of an unspeakable wealth of thought" is linked specifically to the expressive properties of music. The aesthetical ideas in music do, after all, correspond to a theme "which produces the dominating affection in the piece." 23 Perhaps Kant's linkage of the aesthetical ideas conveyed in music to "bodily sensations" ( $§ 54$, quoted above) is an underdeveloped attempt to provide a stronger physical basis for the natural and transcultural effect of music on the emotions.

Kivy rejects the notion that Kant sought, in his doctrine of aesthetic ideas, to ascribe a content to music. ${ }^{24}$ Yet we can question the view that Kant meant the aesthetic ideas conveyed by music to be its form only, without thereby suspecting Kant of attributing content to music. The fact that Kant was unlikely to have thought that music possessed semantic content need not stop us from using his doctrine of aesthetic ideas to make sense of some listeners' propensity to hear music as meaning-bearing. An approach from a different source-Nelson Goodman's conception of art as a symbolic system-may help us here. Much of Goodman's discussion of art focuses on the logic of the denotative relationships-representation, exemplification, and metaphor-inherent in works of art and discovered through engagement with them. Goodman says comparatively little about the process by which we come to appreciate those relationships or their role in aesthetic experience. His approach is thus asymmetrical to Kant's, who devotes most of the Critique of Judgement to a consideration of the mental process operative in understanding art and says comparatively little about artworks themselves.

According to Goodman, artworks possess syntactic and semantic density. ${ }^{25}$ Semantic density is relevant for our purposes. If a symbol system is semantically dense, then for every two characters " $\mathrm{C}$ " and " $\mathrm{C} *$ " that do not have identical compliance classes and every object that 
does not comply with both, it is theoretically impossible to determine that the object does not comply with one or the other. ${ }^{26}$ The opposite of semantic density is semantic finite differentiation. While the standard notation of music displays finite differentiation-a trained listener will be able to determine the notational symbol for a given musical tone and relative durationmusical works as heard are semantically dense. That is, there is no one-to-one relationship between the elements of the music and the elements of the world. Each musical work can be seen as having a different symbolic structure and as utilizing different semantic relationships. The denotative relationships that are found in artworks-representation, expression, and exemplification - are not universal or immutable. They must be "decoded" in each artwork we encounter, although knowledge of the artistic tradition and operative conventions will help us gain a better understanding of the work in question. For example, an ascending chromatic passage need not signify the same thing in works by different composers, nor even in works by the same composer, nor even twice in the same work. Semantic density ensures that we will never be able to say exactly what a particular musical passage conveys.

This is not to suggest that Kant had anything like Goodman's account of art as a symbol system in mind, or that Goodman needs Kant's analysis of aesthetic ideas to round out his own thought. However, bringing the two together in such a way is suggestive and is not precluded by anything either says. If we take seriously Kant's contention that music denotes aesthetic ideas, and accept Goodman's claim that the symbol systems of artworks are dense rather than articulate, we can begin to see why some ascribe semantic content to music. Imagine a listener who hears such a passage in the context of a work with which she is fairly familiar. She has a sense that the passage holds some greater significance within the overall structure of the work. The "dense" nature of music makes it difficult for her to say exactly what the passage signifies, and unlikely that there is any one "correct" answer. Her knowledge about the work-including its title, information about the composer, and the circumstances of its composition-may lead her to favor one possible interpretation over another.
So, one consequence of music's semantic density is the phenomenon of specificity. That is, we are not able to come up with a precise term or phrase to indicate what a listener is supposed to experience; nor are we able fully to convey in language all of a work's aesthetically relevant features and what these features mean to us. The paucity of our language for describing music (as well as other art forms) means that ordinary language cannot fully convey what many listeners would find most meaningful in a musical passage. While poetic language may be more effective than literal language in aesthetic contexts, no one would believe that a verbal description could replace an encounter with the artwork. One has to hear or see for oneself. ${ }^{27}$ Yet it is important to note that this phenomenon says as much about art as it does about language. The paucity of language in aesthetic contexts is underwritten by the epistemic opacity of semantically dense symbol systems. We cannot know what a feature symbolizes, and so we cannot say what it is in words either. Even if (per impossible) we had a language that was fully adequate to describe music, we would still not know which terms to apply.

Both the language we use to describe music and musical features themselves can be ambiguous. Of course, not all ambiguity is aesthetically relevant. In certain contexts, "he went to the bank" might be unclear between departure to the shore or to a financial institution. A word or phrase may be ambiguous because it admits of several meanings (as in my example), or because it is used in a nonstandard way. This latter "poetic" form of ambiguity is of limited use in discussing music, as not every musical feature has an unambiguous "standard" usage. ${ }^{28}$

Let me offer a more specific example of how music might express aesthetic ideas. Recall Scruton's claim that Bach's D Minor Chaconne for solo violin provides an effect of "titanic strain, as of a giant Atlas, bearing the burden of the world's great sadness." Let us assume for the moment that Scruton's description does in fact capture some of the music's structural and expressive properties. "The world's sadness" is a rational idea that is not given in experience. A competent performance of Bach's Chaconne will inspire much thought in a listener. Some of these thoughts will not be adequately expressed by any concept; that is, the music will express 
aesthetic ideas. The particular aesthetic ideas that the Chaconne expresses, while not adequately conveyed in language, might include the inevitability of suffering, the contingency of human life, and the psychic strain brought about by acknowledging these. The aesthetical attribute by which these ideas are evoked is the form of the Chaconne-a series of rhythmic pitches, as perceived by a listener. A different aesthetic form (the series of rhythmic pitches that underlie another musical work, or even different patterns of emphasis in a different performance of the Chaconne) would inspire different aesthetic ideas. The type of ambiguity I have been invoking with relation to the Bach Chaconne is related to semantic density, rather than to deviation from accepted usage.

Interpreting Kant's conception of aesthetic ideas as I have done helps us to see how it is that music could be heard as meaning-bearing without making it necessary to accept the hypothesis that music is literally a language. Composers and performers, in making their distinctive contributions to the art of music, use aesthetical attributes-form and expression-to give works and performances the particular characters that they have. In so doing, they present aesthetic ideas-representations in sound-thus encouraging mental activity in listeners. This mental activity can take many forms, but may include contemplation of Kantian rational ideas. These rational ideas, however, cannot be adequately represented, neither in sound, nor by paint and canvas, nor in stone. Moreover, they cannot be cognized as knowledge, so their interpretation and expression in language is necessarily uncertain. Yet while the semantic content of a particular work will necessarily be open to interpretation, it does not follow that interpretation is hopelessly relativistic or merely whimsical. Aesthetic ideas "reside" in a work's form, and so are liable to the demand of intersubjective agreement. Hence, descriptions or interpretations that are not reflective of a work's form must be rejected as inadequate.

Since music does not carry semantic meaning in the more straightforward way in which natural languages do, there will likely always be disagreement over the meaning of particular musical passages. I have said little about how knowledge of such things as a musical work's title, its expressive properties, or the historical and cultural context in which it was composed could help us understand what, if any, extramusical meaning it might have. The larger questions of what it is to understand a musical work or performance and how this understanding is achieved will have to be set aside for another time. Instead, I have sought to uncover the grounds for the possibility of semantic or cognitive content in music and to answer the question of why at least some listeners "hear" meaning when they listen to music. ${ }^{29}$

\section{JEANETTE BICKNELL}

Department of Philosophy

York University

Ontario, Canada M3J 1P3

INTERNET: bicknellj@hotmail.com

1. Stephen Davies has discussed and evaluated various positions on the relationship between music and language in Musical Meaning and Expression (Cornell University Press, 1994), pp. 1-49.

2. For example, M. Beardsley, "Understanding Music," in On Criticizing Music: Five Philosophical Perspectives, ed. Kingsley Price (Johns Hopkins University Press, 1981), pp. 55-73; Frances Berenson, "Interpreting the Emotional Content of Music," in The Interpretation of Music, ed. Kingsley Price, pp. 61-72; Stanley Cavell, "Music Discomposed," in Must We Mean What We Say? A Book of Essays (Cambridge: Cambridge University Press, 1976), pp. 180-212; David J. Elliot, "Music as Knowledge," The Journal of Aesthetic Education 25 (1991): 21-40; Rom Harre, "Is There a Semantics for Music?" in The Interpretation of Music, ed. Kingsley Price, pp. 203-213; Vladimir Karbusicky, "The Anthropology of 'Semantic Levels' in Music,' Acta Philosophica Fennica 43 (1988): 54-69; Thomas Carson Mark, "On Works of Virtuosity," The Journal of Philosophy 77 (1980): 28-45; Graham McFee, "Meaning and the Art Status of "Music Alone,"' The British Journal of Aesthetics 37 (1997): 31-46; Anthony Newcomb, "Action and Agency in Mahler's Ninth Symphony, Second Movement," in Music and Meaning, ed. Jenefer Robinson (Cornell University Press, 1997), pp. 131-153; Jay Newman, "The Philosophical in Music," The Music Review 41 (1980): 302-308; Kingsley Price, "Does Music Have Meaning?" The British Journal of Aesthetics 28 (1988): 203-215; and Donald Walhout, "Music and Moral Goodness," The Journal of Aesthetic Education 29 (1995): 5-16.

3. Roger Scruton, The Aesthetics of Music (Oxford: Clarendon, 1998), p. 452.

4. Susan McClary, Feminine Endings: Music, Gender, and Sexuality (University of Minnesota Press, 1991), p. 128.

5. Alexander Ivashkin, Alfred Schnittke (London: Phaidon, 1996), p. 215.

6. Ibid., p. 215

7. Ivan Hewett, "Screams Inside a Circle of Fifths," review of Arvo Pärt by Paul Hillier and Henryk Gorecki by 
Adrian Thomas, in Times Literary Supplement (24 October 1997): 21.

8. James O. Young, “The Cognitive Value of Music,” The Journal of Aesthetics and Art Criticism 57 (1997): 41-54.

9. Ibid., p. 48.

10. I will not take up the point, noted by Young, that not all listeners experience emotions listening to music.

11. Kendall L. Walton, "What is Abstract about the Art of Music?" The Journal of Aesthetics and Art Criticism 46 (1988): 351-364.

12. Peter Kivy, Philosophies of Arts (Cambridge: Cambridge University Press, 1998), pp. 181-183.

13. Hans Eggebrecht on Bach's The Art of the Fugue and David P. Schroeder on Haydn's London Symphonies.

14. Kivy, Philosophies of Art, p. 169.

15. Ibid., p. 165.

16. Ibid., p. 175.

17. Jerrold Levinson, "Musical Profundity Misplaced," The Journal of Aesthetics and Art Criticism 50 (1992): 5860.

18. Immanuel Kant, Critique of Judgement, trans. J. H. Bernard (New York: Hafner Press, 1951), § 49. Further references (to section numbers) will be given in brackets in the text.

19. Peter Kivy, "Kant and the Affektenlehre: What $\mathrm{He}$ Said, and What I Wish He Had Said," in The Fine Art of
Repetition (Cambridge: Cambridge University Press, 1993), pp. 252-253.

20. Kivy, "Kant and the Affektenlehre," p. 258.

21. Ibid., p. 263.

22. Ibid., p. 256.

23. I assume that by "theme" Kant is here referring to a musical theme.

24. Kivy, "Kant and the Affektenlehre," pp. 254-255.

25. Nelson Goodman, Languages of Art (London: Oxford University Press, 1969), p. 252.

26. Ibid., p. 152

27. On this point see Arnold Isenberg, "Critical Communication," The Philosophical Review 58 (1949): 330-344.

28. I am grateful to one of the journal's anonymous referees for pressing me to clarify the points made in the previous two paragraphs.

29. Earlier versions of this paper were presented at the Canadian Philosophical Association Annual Congress, May 2000, and at the Northwest Conference on Philosophy, November 2000. I am grateful to these audiences for comments and encouragement, and especially to John Heintz and Thompson Faller for prepared commentaries. I would also like to thank Evan Cameron, Joseph Gonda, Robert Hanna, Ian Jarvie, and the prize committee for the 2001 John Fisher Memorial Prize for comments and suggestions on earlier versions of the paper. 